sible. Most of these patients are suffering from infectious conditions which in well-housed family circumstances would not require hospital admission either by reason of danger of infection, severity of disease, or because treatment could only be obtained in hospital.

In fact, of 431 patients admitted to the Western Hospital from this borough during 1962, only 21 were suffering from diseases notifiable by statute (10 of these being food-poisoning), and only 52 were suffering from diseases notifiable by regulation. The remaining 358 patients were suffering from non-notifiable infections such as mumps, chicken-pox, rubella, glandular fever, etc., for which isolation and/or treatment could not possibly be provided in the place at which they were living. In many cases they would not have been allowed to remain in residence.

Without expressing any views on the advisability or otherwise of trying to isolate dangerous notifiable infectious disease in general hospitals, and disregarding the possibility of epidemics or the recrudescence of virulence in diseases such as scarlet fever or measles, I suggest that it is essential to make adequate provision of infectious disease accommodation to which patients with notifiable and non-notifiable infectious conditions can be admitted when their housing circumstances preclude their isolation and treatment at home. It seems certain that if the Hospital Plan is implemented the very limited isolation accommodation proposed will be quite inadequate to accommodate the volume of cases of the type mentioned above.--I am, etc.,

Public Health Department, Royal Borough of Kensington,

\section{Diagnosis of Acute Appendicitis}

Sir,--We should be grateful for the exhaustive study of acute appendicitis in childhood by Dr. R. H. Jackson (August 3 , p. 277), and valuable lessons can be learnt from it. I think, however, that one of his conclusions may not be justified. He says that "in making the diagnosis of acute appendicitis the history of the disease is of less help to the doctor than the physical examination."

This may be true in the case of very young children and may be what Dr. Jackson intended to convey. I do not think it is true in older children, who can give good factual histories, and it certainly does not apply to adults. In fact the accurate diagnosis of acute appendicitis and many other acute abdominal conditions can often be made on the history while physical signs are misleading or absent. For instance, in acute appendicitis there may be little or no tenderness when an inflamed appendix is tucked well away from the somatic nerve supply of the abdominal wall behind the caecum or mesentery of the small gut.

Physical signs are of course all-important but must be considered together with the history. My own experience shows that accurate history-taking and interpretation of the history are often the vital factors in diagnosis.-I am, etc.,

London W.1.

$$
\text { E. E. O’Malley. }
$$

\section{Toxicity of Lignocaine}

SIR,---There has been correspondence recently concerning the toxicity of lignocaine. On this matter I would agree with those critics who state that those complaining have been using too strong a solution and that some effects described are essentially vasovagal.

Since the introduction of lignocaine I have used it for at least 5,000 operations, including about 100 gastrectomies, 150 cholecystectomies, about 100 prostatectomies, 70 or 80 Fothergill-type operations, and a good many colonic and other abdominal procedures, also numerous varicose veins and hernias. In all these, patients have been adequately premedicated with morphine, hyoscine, and sometimes pethidine. Minor surgery on out-patients is done without premedication.

In all this work I have yet to see gross toxic reaction to lignocaine, though we do notice an occasional mild bradycardia. Toxic reactions to adrenaline do occur from time to time, no more and no less often than when procaine was the anaesthetic drug, but have never been severe enough to require any treatment. For all this work the standard solution is $0.25 \%$ lignocaine, which is a fully effective anaesthetic agent. Adrenaline is added for all major work in the proportion of 1 in 200,000 in normotensives, 1 in 400,000 in hypertension and in certain other instances. The maximum quantity initially is up to $200 \mathrm{ml}$., but if necessary a further $100 \mathrm{ml}$. without adrenaline or $200 \mathrm{ml}$. with 1 in 400,000 adrenaline will be used to supplement anaesthesia or aid dissection.

With due respect to anaesthetists I prefer to do much of my work with local anaesthetic alone owing to the vast reduction in blood loss and greater ease of dissection-for example, in gastrectomies, prostatectomies, and vaginal repair work. In this hospital $0.5 \%$ solution is put up in $10-\mathrm{ml}$. containers, as some prefer it for finger work. I use it only for blocking major nerve trunks-for example, sciatic, when exposed in the course of an amputation.

A $2 \%$ solution without adrenaline is used to pour into the peritoneal cavity where a splanchnic block is not convenient and roaming round to explore the abdomen is necessary. The quantity is normally $25 \mathrm{ml}$. I will use more if, as in intestinal obstruction, a good deal spills out immediately after introduction.

I am writing this because I think it would be most unfortunate if this drug were to get a bad reputation. I believe that when properly used it is exceedingly safe.-I am, etc.,

\section{STEPHEN BARClay.}

Grey Hospital,

Greymouth, New Zealand.

\section{Collapse after " Parstelin"}

SIR,-With reference to the case reported under this heading by Drs. G. A. Low-Beer and D. Tidmarsh (September 14 , p. 683) it is noted that iproniazid (a monoamine-oxidase inhibitor) was given for three weeks until four days before the patient's death, when "parstelin" (tranylcypromine and trifluoperazine) was substituted.

In view of the well-known delayed excretion of monoamine-oxidase inhibitors, resulting in their presence in the body up to seven days after cessation of therapy, and their established property of potentiating the action of other drugs, especially other monoamine-oxidase inhibitors and central-nervous-system depressants, I would suggest that persistence of the action of iproniazid (a drug well known for its potential toxicity) might well have been responsible (in part at least) for the patient's death rather than any effect of parstelin or ephedrine either separately or in combination.I am, etc.,

London S.W.19.

H. LANTIN.

SIR,- The letters from Dr. J. C. Gates and from Drs. G. A. Low-Beer. and D. Tidmarsh (September 14, p. 683) raise some points of interest. Although Dr. Gates is correct in thinking that fluid retention does occur during the taking of tranylcypromine, it is rare and unassociated with paroxysmal side-effects. The diuresis referred to is misleading, since I have observed no change in urine output in the 24 hours following these effects in four patients. The sudden voiding of large quantities of urine after the attack subsides is more likely to be due to extraneous factors, such as inhibition of the bladder during the attack by fear. The effects of tranylcypromine on the sympathetic nervous system are complex. ${ }^{1-s}$ They include pressor effects which are probably central in origin and sympathetic blockade which is peripheral.

The death reported by Drs. Low-Beer and Tidmarsh raises points of greater importance. I believe that very few deaths have occurred during treatment with tranylcypromine alone, though many have occurred with the concomitant use of other drugs. The chief offenders are imipramine $e^{4-6}$ or pethidine ${ }^{7}$ or amphetamine-like agents. ${ }^{78}$ The synergism between tranylcypromine and amphetamine is well documented, and in view of the chemical and pharmacological similarity between these two drugs and between them and ephedrine it is not surprising to receive Dr. Low-Beer's and Dr. Tidmarsh's report. All three drugs inhibit amine oxidase, contain a propylamine side-chain, are central nervous stimulants, and are sympathomimetic. ${ }^{10}$ Tabulation of their side-effects shows them to be identical except that tranylcypromine is alone in causing the paroxysmal ones. ${ }^{12}$

It is likely that tranylcypromine produces its cardiac effects by interfering 
with the tissue-buffering mechanism for storage of catechol amines. Under these circumstances it is also likely that the tissue monoamine system is more sensitive to the action of ephedrine and amphetamine.

It is clear that tranylcypromine should never be given either in the form of "parstelin" (tranylcypromine and trifluoperazine) or of " parnate" (tranylcypromine) within one to two weeks of giving ephedrine or amphetamine as well. In view of the pharmacological action of the drug on so many systems it should probably not be given with anything else at all, at any rate in the present state of our knowledge.

The side-effects of tranylcypromine are due to amine-oxidase inhibition, but there is comparatively little to suggest that this is true of its antidepressant action. One hopes that it will be possible to separate these effects, since the practical difficulty of ensuring that a patient will not consume other tablets as well as tranylcypromine makes the drug a liability in practice. Although all these effects have been known since 1960 they are often still unrecognized.-I am, etc.,

London S.W.11.

C. W. Burke.

1 Gertner, S. B., J. Pharmacol. exp. Ther., 1961, 131, 223.

2 Horwitz. D.. and Sjoerdsma, A., Proc. Soc.

exp. Biol. (N.Y.), 1961, 106, 118

pencer, J. N.. Porter, M.. Froehlich, H. L. (1960, 19, 277.

Babiak, W.. Canad. med. Ass. J., 1961, 85, 377 Ass., 1961, 177, 68. E. F., J. Amer. med. , 1961, 177. 68

85, 711, D. S., Canad. med. Ass. J., 1961

Womack. A. M., Brit. med. J., 1963, 2, 366.

Zeck, P., Med. J. Aust., 1961, 2, 607. Cook, R. E., Tedeschi, D. H., Ames, P. L. Cook. L., Mattis, P. A. and Fellows, E J. Proc. Soc. exp. Biol. (N.Y.). 1959, 102, 380 10 Green, H.. and Erickson, R. W., J. Pharmacol.

11 Lees, F., and Burke, C. W., Lancet, 1963, 1, 13.

\section{Side-effects of Tranylcypromine}

SIR,-In view of the recent reports of serious side-effects associated with tranylcypromine (" parnate ") therapy, including the fatality reported in your columns by Dr. A. M. Womack (August 10, p. 366), we have thought it worth communicating our experience with this drug in the course of a two-year controlled comparative out-patient trial of four antidepressants: tranylcypromine, imipramine, amitriptyline, and isocarboxazid. A full account of this work is to be published elsewhere shortly.

There were 38 patient trials of parnate. The dose prescribed was $10 \mathrm{mg}$. twice daily for five days, then $20 \mathrm{mg}$. twice daily. 15 patients $(39 \%)$ experienced severe side-effects ; of these, $12(32 \%)$ as a result stopped the drug or were advised to do so. Nine patients $(24 \%)$ experienced headache, seven the characteristic sudden, severe, incapacitating type, and two others milder headaches. Three of those with headache were able to continue the drug without further trouble and without reduction in the dose of $20 \mathrm{mg}$. twice daily, four refused to continue, and two had further headaches in spite of reduced dosage so the drug was discontinued. Of interest was the unexpected development of the headache in some patients who had been taking $40 \mathrm{mg}$ daily for long periods (three, eight, and twelve weeks) without trouble. In five other patients other symptoms (palpitations, chest tightness, giddiness, visual disturbance, nausea, drowsiness or hesitancy of micturition) occurred with smaller doses, 20 to $30 \mathrm{mg}$. daily, within a week or two of starting medication. In these cases also the patients either stopped taking the drug or were advised to do so. One patient, after taking a number of tablets irregularly over the course of a month, developed a hypoplastic anaemia. This may not have been attributable to the drug, since the patient gave a history of a previous episode of obscure anaemia.

We found the drug an effective antidepressant in the dosage we used, but not more so than isocarboxazid, which was comparatively free from side-effects. On the basis of our experience during this trial, together with the reports that have appeared of more serious sequelae to the use of tranylcypromine, we have grave doubts about the advisability of further administration of this substance, unless some explanation can be found which would enable preventive measures to be taken.-We are, etc.

\section{P. W. RICHMOND. A. H. ROBERTS. \\ Atkinson Morley's Hospital, \\ London S.W.19.}

\section{Foetal Death after Pethidine and Promazine}

SIR,- - Having used the combination of pethidine and promazine as sedation in labour for the past five years I was disturbed at the report by Mr. A. G. Amias and Mr. D. Fairbairn of foetal death following its use (August 17, p. 432). I trust that the report will not discourage administration of the combination which has been proved effective. ${ }^{12}$

It does, however, emphasize that care must be taken in the amount of drugs administered, especially intravenously. Pethidine $100 \mathrm{mg}$. given intravenously in a single injection is certainly not without hazard and any effect is bound to be potentiated when promazine is given simultaneously. One may doubt the need of any premedication prior to surgical induction of labour, but the intravenous use of such high doses as pethidine $100 \mathrm{mg}$. and promazine $50 \mathrm{mg}$. would seem unwarranted, since it has obviously no advantage over a suitable intramuscular injection given about an hour previously.

In what must be now over 1,000 cases I personally have seen no serious effect from the giving of pethidine and promazine $(50 \mathrm{mg}$. of each) intravenously in a single injection. I have seen a case similar to the one described where in error a patient was infused with $100 \mathrm{mg}$. of pethidine and $100 \mathrm{mg}$. of sparine in $500 \mathrm{ml}$. of $10 \%$ glucose within 15 minutes.
The patient, who was established in labour, looked almost moribund with a thready rapid pulse, hypotension, and reduction in respiratory rate. The foetal heart rate rose to $180 / \mathrm{min}$. It was decided to do nothing till the effect of the drug had worn off, and the patient delivered herself spontaneously eight hours later of an active healthy baby. At no time was there evidence of meconium staining of the liquor amnii.

It is always easy in retrospect to criticize the treatment of a case, but in that described by $\mathrm{Mr}$. Amias and $\mathrm{Mr}$. Fairbairn it might have been better not to have carried out caesarean section but to have waited till the effect of the drugs had subsided, as reported above. The actual operation within an hour of the initial injection may have played a part in the asphyxial death of the baby. Preeclampsia associated with post-maturity may also have contributed to intrauterine asphyxia.

With regard to routine sedation in labour the intramuscular administration of pethidine (maximum $100 \mathrm{mg}$.) and promazine (maximum $50 \mathrm{mg}$.) by single injection is safe in the hands of both midwife or medical attendant, whereas the intravenous administration of drugs during labour should be under experienced obstetrical supervision. As a general rule pethidine $50 \mathrm{mg}$. and promazine $50 \mathrm{mg}$. in a single intravenous injection would seem to be the maximum which should be given, and we have not found higher dosage necessary.

Where there is experienced obstetrical supervision I should like to advocate the extension of intravenous sedation in labour. It not only cuts down the total amount of analgesia required but it gives immediate relief to the patient and not 15 minutes or five pains later as with intramuscular injections. The psychological effect in the patient is obvious. -I am, etc.

\section{Department of Midwifery, JoHN MACVICAR.}

\section{REFERENCES}

MacVicar, J., and Murray, M. H., Brit. med. J. 2 Mathews, A. E. B., ibid., 1963, 2, 423.

\section{Increased Libido with Chlorprothixene}

SIR,-There have been occasional reports $^{12}$ in the literature of chlorprothixene ("taractan") having an excitatory, rather than a tranquillizing, effect on patients. $\mathrm{Ma}$ and $\mathrm{Crandel}^{3}$ have also reported that a patient developed increased libido following the administration of the drug.

I wish to draw to your attention a similar effect upon' a 37-year-old married woman suffering from manic depressive psychosis. This patient from the age of 17 years has had numerous attacks of depression and mania. Over the past two years the attacks have been circular, two weeks of depression alternating with two weeks of mania.

In June, 1962, chlorprothixene $50 \mathrm{mg}$. t.d.s. was prescribed to be taken during the manic phase. A few days after taking the 